\title{
Clinical factors predictive of appropriate treatment in COPD: a community hospital setting
}

\author{
Sukanya Tongdee ${ }^{1}$, Bundit Sawunyavisuth ${ }^{2}$, Wattana Sukeepaisarnjaroen ${ }^{3}$, Watchara Boonsawat ${ }^{3}$, Sittichai Khamsai ${ }^{3}$, \\ Kittisak Sawanyawisuth ${ }^{3}$ \\ ${ }^{1}$ Department of Medicine, Chumpae Hospital, Khon Kaen - Thailand \\ ${ }^{2}$ Department of Marketing, Faculty of Business Administration and Accountancy, Khon Kaen University, Khon Kaen - Thailand \\ ${ }^{3}$ Department of Medicine, Faculty of Medicine, Khon Kaen University, Khon Kaen - Thailand
}

\begin{abstract}
Background: Chronic obstructive pulmonary disease (COPD) is a common respiratory disease. The appropriate treatment according to the Global Initiative for Chronic Obstructive Lung Disease (GOLD) guideline was 19-60\%. However, there are limited data on predictors of appropriate treatment in patients with COPD. This study aimed to evaluate risk factors of appropriate treatment in patients with COPD according to the GOLD guideline in a realworld community setting.

Methods: This is a retrospective study conducted at a community hospital. Inclusion criteria were adult patients diagnosed as COPD treated at a COPD clinic. The primary outcome was the appropriate treatment, defined by correct pharmacological treatment by the GOLD guideline according to the ABCD severity assessment. Clinical predictors of appropriate treatment were executed by stepwise multivariate logistic regression analysis.

Results: 136 patients with COPD met the study criteria. Of those, 100 patients had inappropriate treatment according to the GOLD guideline. Three factors were independently associated with the appropriate treatment including number of admissions, modified Medical Research Council (mMRC) score, and CAT score. These factors had adjusted odds ratio of 3.11, 2.86, and 1.26, respectively. Causes of inappropriate treatment were unavailability of long-acting muscarinic antagonist (LAMA) (51 patients; $79.69 \%)$, treated by inhaled corticosteroid (ICS) alone (12 patients; $18.75 \%$ ), and treated with only bronchodilator (1 patient; $1.56 \%$ ).

Conclusions: Appropriate COPD patients' treatment according to the GOLD guideline was $26.47 \%$ in community setting. Factors associated with severity of COPD were associated with prescribing appropriate treatments.
\end{abstract}

Keywords: CAT, hospitalization, mMRC

\section{Introduction}

Chronic obstructive pulmonary disease (COPD) is a respiratory disease mainly caused by smoking. Patients with COPD suffer from several symptoms, exacerbations, or hospitalizations leading to $2.6 \%$ of disability-adjusted life years (DALYs) and at least 3.2 million deaths globally (1). Diagnosis of COPD

Received: July 7, 2021

Accepted: October 19, 2021

Published online: November 13, 2021

Corresponding authors:

Sittichai Khamsai and Kittisak Sawanyawisuth

123 Mitraparp Road

Department of Medicine

Faculty of Medicine

Khon Kaen University

Khon Kaen, 40002 - Thailand

sittikh@kku.ac.th and kittisak@kku.ac.th can be confirmed by evidence of incomplete irreversible airflow limitation without other causes. Treatment of COPD comprises both pharmacological and nonpharmacological modalities such as smoking cessation. Uncontrolled COPD may lead to COPD exacerbations and mortality (2). A study of 73,106 patients with COPD found that the mortality rate was $50 \%$ at 3.6 years after hospitalization (3), while another study found that in-hospital mortality rate was $2.6 \%$ (4).

There are several factors associated with COPD control such as COPD severity, patient compliance, correct inhaler technique, or nonpharmacological treatment $(5,6)$. Even though patients with COPD had medication adherence of $51.0 \%, 85$ out of 549 patients or only $15.5 \%$ were under control (7). Another factor that may be associated with COPD symptom control is appropriately prescribed medication $(6,8,9)$. An undertreatment according to the guideline increases risk of COPD exacerbation with a coefficient of $-0.179(p<0.001)$ (9). The Global Initiative for Chronic Obstructive Lung Disease (GOLD) guideline recommends 
various pharmacological regimens based on COPD severity (10). In real practice, the appropriate treatment according to the GOLD guideline was $19-60 \%(9,11,12)$. However, there are limited data on predictors of appropriate treatment in patients with COPD. This study aimed to evaluate risk factors of appropriate treatment in patients with COPD according to the GOLD guideline in a real-world community setting.

\section{Methods}

This study was a retrospective study conducted at Chumpae Hospital, the largest community hospital in Khon Kaen province, Khon Kaen, Thailand. The inclusion criteria were adult patients who were diagnosed with COPD and treated at the COPD clinic. The diagnosis of COPD was made according to the GOLD guideline (10). The study period was between May and November 2019. The study protocol was approved by the institutional review board, Ministry of Public Health, Khon Kaen Branch, Thailand (61165).

Eligible patients were enrolled from clinical charts and evaluated for baseline characteristics, smoking history, risk factor for COPD, symptoms, chest $x$-ray, pulmonary function test, COPD type, 6-minute walk test (6MW), history of exacerbations, history of admission, and COPD assessment. History of cough was defined by the presence of cough for more than 2 weeks, while productive sputum more than 2 months was recorded. COPD assessment was evaluated by using modified Medical Research Council (mMRC), COPD Assessment Test (CAT), and COPD classification by the GOLD guideline or $A B C D$ assessment. The primary outcome of the study was the appropriate treatment, which was defined by correct pharmacological treatment by the GOLD guideline to category $A$ to $D$ : a bronchodilator for group $A$; a long-acting bronchodilator (long-acting beta2-agonists: LABA or long-acting muscarinic antagonist: LAMA) for group B; LAMA for group C; and LAMA or LAMA plus LABA or inhaled corticosteroid (ICS) plus LABA for group D. Treatment other than this recommendation in a particular category was defined as inappropriate treatment. The inappropriate treatment was also classified as under- and overtreatment according to the recommendation for each category. Note that information retrieved for the study was at the initial therapy of each patient.

\section{Statistical analyses}

Patients were categorized into two groups by appropriateness of treatment. The studied variables were compared between both groups by descriptive statistics. For numerical variables, mean and SD was reported and compared between groups by using independent t-test or Wilcoxon Rank Sum test where appropriate. Numbers and percentages of each categorical variable were reported and compared between groups by Chi Square test or Fisher Exact test where appropriate. Clinical predictors of appropriate treatment were executed by stepwise multivariate logistic regression analysis. Those factors with a $p$ value of less than 0.20 by univariate logistic regression were put in the subsequent multivariate logistic regression analysis. The goodness of fit of the final model was tested by Hosmer-Lemeshow method.
The statistical analyses were executed by the STATA software (College Station, Texas, USA).

\section{Results}

There were 136 patients with COPD who met the study criteria. Of those, 100 patients $(73.53 \%)$ were with inappropriate treatment according to the GOLD guideline. Between those with appropriate and inappropriate treatment groups, there were two significant factors in terms of baseline characters including cough and sputum production (Tab. I). The appropriate treatment group had higher proportions of patients with cough and sputum production than the inappropriate treatment group $(77.78 \%$ vs. $54.00 \%$; and $80.56 \%$ vs. $60.00 \%$, respectively).

TABLE I - Baseline characters of patients with chronic obstructive pulmonary diseases (COPD) categorized by receiving appropriate treatment

\begin{tabular}{lccc}
\hline Factors & $\begin{array}{c}\text { Inappropriate } \\
\mathbf{n}=\mathbf{1 0 0}\end{array}$ & $\begin{array}{c}\text { Appropriate } \\
\mathbf{n = 3 6}\end{array}$ & $\begin{array}{c}\mathbf{p} \\
\text { value }\end{array}$ \\
\hline Mean (SD) age, years & $64.51(8.83)$ & $63.47(10.51)$ & 0.566 \\
Male sex, n (\%) & $94(94.00)$ & $35(97.22)$ & 0.675 \\
Occupation: & $93(93.00)$ & $31(86.11)$ & 0.412 \\
agricultural, n (\%) & & & \\
Diabetes mellitus, n (\%) & $8(8.00)$ & $7(19.44)$ & 0.060 \\
Hypertension, n (\%) & $42(42.00)$ & $17(47.22)$ & 0.588 \\
Dyspnea, n (\%) & $100(100.00)$ & $37(100.00)$ & $\mathrm{NA}$ \\
Cough, n (\%) & $54(54.00)$ & $28(77.78)$ & 0.012 \\
Sputum, n (\%) & $60(60.00)$ & $29(80.56)$ & 0.026 \\
Smoking history, n (\%) & & & 0.992 \\
$\quad$ None & $9(9.00)$ & $3(8.33)$ & \\
$\quad$ Ex-smoker & $72(72.00)$ & $26(72.22)$ & \\
Current smoker & $19(19.00)$ & $7(19.44)$ & \\
Mean (SD) pack-year of & $21.49(15.40)$ & $26.82(29.24)$ & 0.498 \\
smoking & & & \\
Exposure to noxious & $6(6.00)$ & $2(5.56)$ & 0.999 \\
particles, n (\%) & & & \\
Mean (SD) BMl (kg/m²) & $21.17(3.69)$ & $21.90(3.95)$ & 0.446 \\
\hline
\end{tabular}

$\mathrm{BMI}=$ body mass index; $\mathrm{NA}=$ not available.

Between these two groups, the appropriate treatment group had shorter 6MW test (328.05 vs. $353.49 \mathrm{~m})$ and lower mMRC (1.83 vs. 0.96$)$ than the inappropriate treatment group significantly (Tab. II). But the average CAT score (15.88 vs. 7.22 ), average number of exacerbation (2.83 vs. 1.13 times), and average number of admissions (2.83 vs. 1.13 times) were significantly higher in the appropriate treatment group than the inappropriate treatment group (Tab. II) while the post-bronchodilator FEV1/FVC was significantly lower in the appropriate treatment group than the inappropriate treatment group ( 53.19 vs. $57.32 ; p=0.033)$. COPD class $D$ 
TABLE II - Laboratory results and disease status of patients with chronic obstructive pulmonary diseases (COPD) categorized by receiving appropriate treatment

\begin{tabular}{|c|c|c|c|}
\hline Factors & $\begin{array}{c}\text { Inappropriate } \\
n=100\end{array}$ & $\begin{array}{c}\text { Appropriate } \\
n=36\end{array}$ & $\begin{array}{c}\mathbf{p} \\
\text { value }\end{array}$ \\
\hline \multicolumn{4}{|l|}{ CXR, n (\%) } \\
\hline Normal, n (\%) & $53(53.00)$ & $19(52.78)$ & 0.982 \\
\hline Hyperinflation, n (\%) & $36(36.00)$ & $13(36.11)$ & 0.990 \\
\hline $\begin{array}{l}\text { Post-bronchodilator } \\
\text { FEV1, mL }\end{array}$ & $66.86(17.40)$ & $60.30(19.11)$ & 0.061 \\
\hline $\begin{array}{l}\text { Post-bronchodilator } \\
\text { FEV1, \% }\end{array}$ & $6.02(7.00)$ & $6.80(7.21)$ & 0.602 \\
\hline $\begin{array}{l}\text { Post-bronchodilator } \\
\text { FEV1/FVC }\end{array}$ & $57.32(9.17)$ & 53.19 (9.99) & 0.033 \\
\hline COPD type, n (\%) & & & 0.999 \\
\hline Chronic bronchitis & $3(3.00)$ & $1(2.78)$ & \\
\hline Emphysema & $5(5.00)$ & $1(2.78)$ & \\
\hline Mixed & $92(92.00)$ & $34(94.44)$ & \\
\hline $\begin{array}{l}\text { Mean (SD) 6MW, } \\
\text { meters }\end{array}$ & 353.49 (72.91) & $328.05(87.16)$ & 0.222 \\
\hline mMRC, n (\%) & $0.96(0.66)$ & $1.83(0.88)$ & $<0.001$ \\
\hline 0 & $22(22.00)$ & $1(2.78)$ & \\
\hline 1 & $62(62.00)$ & $13(36.11)$ & \\
\hline 2 & $14(14.00)$ & $14(38.89)$ & \\
\hline 3 & $2(2.00)$ & $7(19.44)$ & \\
\hline 4 & 0 & $1(2.78)$ & \\
\hline Mean (SD) CAT & $7.22(5.31)$ & $15.88(5.04)$ & $<0.001$ \\
\hline Exacerbation, n (\%) & $1.13(2.40)$ & $2.83(2.09)$ & $<0.001$ \\
\hline Admission, n (\%) & $0.26(0.75)$ & $1.22(1.17)$ & $<0.001$ \\
\hline Category, n (\%) & & & $<0.001$ \\
\hline A & $42(42.00)$ & 0 & \\
\hline B & $30(30.00)$ & 0 & \\
\hline C & $25(25.00)$ & 0 & \\
\hline D & $3(3.00)$ & $36(100.00)$ & \\
\hline
\end{tabular}

$6 \mathrm{MW}=6$-minute walk test; $\mathrm{CAT}=\mathrm{COPD}$ Assessment Test $; \mathrm{mMRC}=$ modified Medical Research Council dyspnea questionnaire; COPD category by the GOLD guideline.

was also found more in the appropriate treatment group than the inappropriate treatment group (100.00\% vs. $3.00 \%)$.

There were five factors remaining in the final model predictive of appropriate treatment in patients with COPD (Tab. III). Of those, three factors were independently associated with the appropriate treatment including number of admissions, mMRC score, and CAT score. These factors had adjusted odds ratio of $3.11,2.86$, and 1.26 , respectively. The final model had the Hosmer-Lemeshow chi-square of 10.72 $(p=0.218)$, indicating goodness of fit of the model. Causes of inappropriate treatment were unavailability of LAMA
TABLE III - Factors predictive of appropriate treatment in chronic obstructive pulmonary diseases (COPD) treated at community hospital

\begin{tabular}{lcc}
\hline Factors & $\begin{array}{c}\text { Unadjusted odds ratio } \\
\text { (95\% confidence } \\
\text { interval) }\end{array}$ & $\begin{array}{c}\text { Adjusted odds ratio } \\
\text { (95\% confidence } \\
\text { interval) }\end{array}$ \\
\hline Age & $0.99(0.95,1.03)$ & $0.94(0.89,1.01)$ \\
Diabetes & $2.77(0.93,8.31)$ & $3.10(0.46,20.84)$ \\
Admission & $3.73(2.02,6.88)$ & $3.11(1.39,6.97)$ \\
mMRC & $4.47(2.41,8.30)$ & $2.86(1.18,6.94)$ \\
CAT & $1.32(1.19,1.47)$ & $1.26(1.13,1.42)$ \\
\hline
\end{tabular}

Factors in the model included sex, smoking, cough, sputum, body mass index, chest $x$ ray, 6-minute walk test, post-bronchodilator FEV1, post-bronchodilator FEV1/FVC, and exacerbation.

CAT = COPD Assessment Test; $\mathrm{mMRC}=$ modified Medical Research Council dyspnea questionnaire.

(51 patients; 79.69\%), treated by ICS alone (12 patients; $18.75 \%)$, and treated with only bronchodilator (1 patient; $1.56 \%)$. Categorized by COPD category, overtreatment was found in categories $A, B$, and $C$, while undertreatment was reported in categories $B, C$, and $D$ (Tab. IV).

TABLE IV - Proportions of under- or overtreatment by chronic obstructive airway disease category $(n=100)$

\begin{tabular}{lcccc}
\hline Treatment & $\mathbf{A ~ ( n = 4 2 )}$ & $\mathbf{B}(\mathbf{n}=\mathbf{3 0})$ & $\mathbf{C ~ ( n = 2 5 )}$ & $\mathbf{D}(\mathbf{n}=\mathbf{3})$ \\
\hline Undertreatment & 0 & $6(20.00)$ & $2(8.00)$ & $3(100.00)$ \\
Overtreatment & $42(100.00)$ & $24(80.00)$ & $23(92.00)$ & 0 \\
\hline
\end{tabular}

\section{Discussion}

This study showed that the appropriate treatment for patients with COPD was $26.47 \%$ : in category D at $100.00 \%$ (Tab. II). Compared with other three previous studies, this study had appropriate treatment rate comparable with the study at VA hospital in the US (27.2\% vs. $18.7 \%)$ and lower than two studies from tertiary hospitals. In this community hospital setting, patients with category D had highest appropriate treatment rate than others at $100.00 \%$ (Tab. II). This pattern was also found in other studies which may indicate that severe cases of COPD tend to follow the GOLD guideline as they may have severe symptoms and required appropriate and several pharmacological therapies $(10,13)$.

This study also found another similar pattern on appropriate treatment: low appropriate treatment rate in categories $A, B$, and $C$. First, we found that inhaled corticosteroid alone was used in 12 patients or $18.75 \%$. The study from Italy also found that inhaled corticosteroid was overused despite the GOLD guideline that does not recommend it as shown in Table V (11). But, the attending physicians believe that it is more effective. A study from Sweden also found that inhaled corticosteroid was used inappropriately in $45.5 \%$ of patients with COPD regardless of categories: A 33.6\%; B 46.2\%; 
TABLE V - Appropriate treatment in ABCD severity assessment in patients with chronic obstructive pulmonary disease

\begin{tabular}{|c|c|c|c|c|c|c|c|}
\hline Study, year & Country & Setting & Total & A & B & C & D \\
\hline Palmiotti, 2018 & Italy & Pulmonologists & $\begin{array}{c}419 / 693 \\
(60.5 \%)\end{array}$ & $\begin{array}{l}57 / 142 \\
(40.1 \%)\end{array}$ & $\begin{array}{l}110 / 238 \\
(46.2 \%)\end{array}$ & $\begin{array}{c}18 / 41 \\
(43.9 \%)\end{array}$ & $\begin{array}{c}234 / 272 \\
(86.0 \%)\end{array}$ \\
\hline Foda, 2017 & USA & VA and University Hospital & $\begin{array}{c}164 / 878 \\
(18.7 \%)\end{array}$ & $\begin{array}{c}30 / 86 \\
(34.9 \%)\end{array}$ & $\begin{array}{c}19 / 379 \\
(5.0 \%)\end{array}$ & $\begin{array}{l}73 / 292 \\
(25.0 \%)\end{array}$ & $\begin{array}{l}42 / 121 \\
(34.7 \%)\end{array}$ \\
\hline Chan, 2017 & Hong Kong & Tertiary Hospital & $\begin{array}{l}262 / 450 \\
(58.2 \%)\end{array}$ & $\begin{array}{c}1 / 5 \\
(20.0 \%)\end{array}$ & $\begin{array}{l}7 / 164 \\
(1.6 \%)\end{array}$ & $\begin{array}{l}0 / 8 \\
(0 \%)\end{array}$ & $\begin{array}{c}254 / 273 \\
(56.4 \%)\end{array}$ \\
\hline This study & Thailand & Community Hospital & $\begin{array}{c}36 / 136 \\
(26.47 \%)\end{array}$ & $\begin{array}{l}0 / 42 \\
(0 \%)\end{array}$ & $\begin{array}{l}0 / 30 \\
(0 \%)\end{array}$ & $\begin{array}{l}0 / 25 \\
(0 \%)\end{array}$ & $\begin{array}{c}36 / 39 \\
(92.31 \%)\end{array}$ \\
\hline
\end{tabular}

C 54.8\%; and D 71.0\% (14). An inappropriate use of inhaled corticosteroid was also found in $50 \%$ of patients with COPD in the UK (15). Another limitation for community hospital in this study is lack of LAMA in $79.69 \%$ : it may be due to unavailability and cost of LAMA.

Not surprisingly, factors predictive for appropriate treatments were factors indicating severe COPD including hospital admissions, mMRC, and CAT score (Tabs. II and III). Among these three factors, admissions and $\mathrm{mMRC}$ had higher adjusted odds ratios than the CAT score. These may imply that the two factors are slightly stronger predictors for severe COPD than the CAT score $(9,10,13)$. Additionally, hospitalizations may remind physicians to prescribe more proper medications for the patients as they may have more times to assess the patients than in the outpatient setting (16).

This study had some limitations. First, we did not evaluate association of COPD such as obstructive sleep apnea (OSA) or asthma which may result in overprescription of corticosteroids (17-21). Second, the study population was community hospital. The results of this study may not be applied for more complicated COPD patients. Second, there was no follow-up data on long-term outcomes. Finally, inappropriate treatment of not using LAMA was due to unavailability. Other causes of inappropriate treatment were treatment with only ICS (18.75\%) or bronchodilator alone $(1.56 \%)$.

\section{Conclusion}

Appropriate treatment of patients with COPD according to the GOLD guideline was $26.47 \%$ in community setting. Factors associated with severity of COPD were associated with prescribing of appropriate treatments.

\section{Acknowledgments}

The authors would like to thank Research Center in Back, Neck Other Joint Pain and Human Performance (BNOJPH), Khon Kaen University, Khon Kaen, Thailand.

\section{Disclosures}

Conflict of interest: The authors declare that they have no conflicts of interest.

Financial support: None.

\section{References}

1. Soriano JB, Abajobir AA, Abate KH, et al; GBD 2015 Chronic Respiratory Disease Collaborators. Global, regional, and national deaths, prevalence, disability-adjusted life years, and years lived with disability for chronic obstructive pulmonary disease and asthma, 1990-2015: a systematic analysis for the Global Burden of Disease Study 2015. Lancet Respir Med. 2017;5(9):691-706. CrossRef PubMed

2. Kim WJ, Gupta V, Nishimura M, et al. Identification of chronic obstructive pulmonary disease subgroups in 13 Asian cities. Int J Tuberc Lung Dis. 2018;22(7):820-826. CrossRef PubMed

3. Suissa S, Dell'Aniello S, Ernst P. Long-term natural history of chronic obstructive pulmonary disease: severe exacerbations and mortality. Thorax. 2012;67(11):957-963. CrossRef PubMed

4. Dong F, Ren X, Huang K, Wang Y, Jiao J, Yang T. Development and validation of risk prediction model for in-hospital mortality among patients hospitalized with acute exacerbation: chronic obstructive pulmonary disease between 2015 and 2019. Front Med (Lausanne). 2021;8:630870. CrossRef PubMed

5. Bettoncelli G, Blasi F, Brusasco V, et al. The clinical and integrated management of COPD. Sarcoidosis Vasc Diffuse Lung Dis. 2014;31(suppl 1):3-21. CrossRef PubMed

6. Hashimoto N, Wakahara K, Sakamoto K. The importance of appropriate diagnosis in the practical management of chronic obstructive pulmonary disease. Diagnostics (Basel). 2021;11(4): 618. CrossRef PubMed

7. Roche N, Plaza V, Backer V, et al. Asthma control and COPD symptom burden in patients using fixed-dose combination inhalers (SPRINT study). NPJ Prim Care Respir Med. 2020;30(1):1. CrossRef PubMed

8. Fernandes FLA, Cukier A, Camelier AA, et al. Recommendations for the pharmacological treatment of COPD: questions and answers. J Bras Pneumol. 2017;43(4):290-301. CrossRef PubMed

9. Foda HD, Brehm A, Goldsteen K, Edelman NH. Inverse relationship between nonadherence to original GOLD treatment guidelines and exacerbations of COPD. Int J Chron Obstruct Pulmon Dis. 2017;12:209-214. CrossRef PubMed

10. Global Initiative for Chronic Obstructive Lung Disease (GOLD). Global strategy for the diagnosis, management and prevention of COPD, Online (2021, accessed 26 April 2021).

11. Palmiotti GA, Lacedonia D, Liotino V, et al. Adherence to GOLD guidelines in real-life COPD management in the Puglia region of Italy. Int J Chron Obstruct Pulmon Dis. 2018;13:2455-2462. CrossRef PubMed

12. Chan KP, Ko FW, Chan HS, et al. Adherence to a COPD treatment guideline among patients in Hong Kong. Int J Chron Obstruct Pulmon Dis. 2017;12:3371-3379. CrossRef PubMed 
13. Ding B, Small M, Holmgren U. A cross-sectional survey of current treatment and symptom burden of patients with COPD consulting for routine care according to GOLD 2014 classifications. Int J Chron Obstruct Pulmon Dis. 2017;12:1527-1537. CrossRef PubMed

14. Larsson K, Ekberg-Jansson A, Stridsman C, Hanno M, Vanfleteren LEGW. Adherence to treatment recommendations for chronic obstructive pulmonary disease - results from the Swedish National Airway Register. Int J Chron Obstruct Pulmon Dis. 2021;16:909-918. CrossRef PubMed

15. Price $D$, West $D$, Brusselle $G$, et al. Management of COPD in the UK primary-care setting: an analysis of real-life prescribing patterns. Int J Chron Obstruct Pulmon Dis. 2014;9:889-904. CrossRef PubMed

16. Ramakrishnan S, Janssens W, Burgel PR, et al. Standardisation of clinical assessment, management and follow-up of acute hospitalised exacerbation of COPD: A Europe-wide consensus. Int J Chron Obstruct Pulmon Dis. 2021;16:321-332. CrossRef PubMed
17. Sawunyavisuth B. What are predictors for a continuous positive airway pressure machine purchasing in obstructive sleep apnea patients? Asia Pac J Sci Technol. 2018;23: APST-23-03-10. CrossRef

18. Kingkaew N, Antadech T. Cardiovascular risk factors and 10-year CV risk scores in adults aged 30-70 years old in Amnat Charoen Province, Thailand. Asia Pac J Sci Technol. 2019;24:APST-24-04-04. Online

19. Jingmark $S$, Kuhirunyaratn $P$, Theeranut $A$, et al. Subjective well-being and related factors among community-dwelling elderly in Udon Thani Province, Thailand. Asia Pac J Sci Technol. 2020;25:APST-25-01-09. Online

20. Chaiear N, Nirarach K, Kawamatawong T, et al. Proportion of workers having work-related asthma symptoms in a cassava factory, Nakhon Ratchasima province, Thailand. Asia Pac J Sci Technol. 2020;25:APST-25-02-08. Online

21. Mekov E, Nuñez A, Sin DD, et al. Update on asthma-COPD overlap (ACO): a narrative review. Int J Chron Obstruct Pulmon Dis. 2021;16:1783-1799. CrossRef PubMed 